\title{
Event-Related Potential Indicators of the Dynamic Unconscious
}

\author{
Howard Shevrin, ${ }^{1}$ William J. Williams, Robert E. Marshall, \\ Richard K. Hertel, James A. Bond, and Linda A. Brakel \\ Department of Psychiatry and Department of Electrical Engineering and Computer Science, \\ University of Michigan, Ann Arbor, Michigan 48109-0722
}

\begin{abstract}
The present study applies a new method for investigating dynamic unconscious processes. The method consists of (1) selection of words from patient interview and test protocols that in the clinicians' judgments capture the patients' conscious symptom experience (i.e., phobia) and the hypothetical unconscious conflict related to the symptom, (2) subliminal and supraliminal presentation of these words, (3) signal analysis of event-related potentials (ERPs) obtained to the word presentations. Eight phobics and three patients suffering from pathological grief reactions served as subjects. A timefrequency (Williams \& Joeng, 1989) ERP analysis revealed that subjects' ERPs classified the unconscious conflict words better subliminally than supraliminally, while the reverse was true for the conscious symptom words $(t(20)=2.82, p=.011)$. The relationship between frequency and latency revealed a similar mirror image pattern for the unconscious conflict and conscious symptom words $(F(4 / 36)=4.14, p=.007)$. This method demonstrated that objective, brain-based evidence for unconscious conflict can be obtained. (c) 1992 Academic Press, Inc.
\end{abstract}

\section{INTRODUCTION}

As psychology has broadened its interest from the study of overtly observable behavior to include the role of consciousness, it has become apparent that consciousness itself cannot be understood without positing the existence of unconscious processes (Shevrin \& Dickman, 1980; Kihlstrom, 1984, 1987). At present there are two views of the nature of these unconscious processes: cognitive and dynamic. The cognitive perspective stresses the role of unconscious computational and associative processes in perception, memory, judgment, and attention as general psychological functions. Psychoanalysis stresses the role of unconscious affective and motivational forces in a state of conflict varying as a function of personal history and the nature of defensive organization. These views, although different in emphasis, can be seen as complementary.

In a paper exploring the implications of this shift from an interest in overt behavior to the investigation of unconscious processes, Shevrin and Dickman (1980) advanced three propositions: (1) The initial stage for all stimuli occurs outside of consciousness, (2) this initial stage outside of consciousness is psychological in nature, is active in its effect on consciousness, and can be different

\footnotetext{
${ }^{1}$ To whom reprint requests should be addressed at University of Michigan Medical Center, Department of Psychiatry, Riverview Building, 900 Wall Street, Ann Arbor, MI 48109.
} 
from conscious experience in its principles of operation, (3) consciousness of a stimulus is a later and optional stage.

These propositions led to specifying three factors that determine the emergence of a stimulus into consciousness: (1) Stimulus factors (e.g., loudness, brightness, figural coherence, meaning, etc.), (2) state factors (e.g., positive interest, level of arousal, sleep stage, fatigue, distractibility, etc.), (3) motivational factors (e.g., avoidance of anxiety, guilt, conflict, interest, etc.). Cognitive research has mainly dealt with the role of stimulus factors in unconscious processing, including prominently stimulus meaning as in the use of words and pictures. Research within a psychoanalytic frame of reference has concentrated on the third set of factorsaffect, defensive organization, motivation, and conflict. Interestingly, very little research has been done on state factors (however, see Shevrin \& Fisher, 1967; Stross \& Shevrin, 1967; Castaldo \& Shevrin, 1970).

\section{THE ROLE OF SUBLIMINAL PERCEPTION}

As unconscious processes have become of increasing interest to psychology, the use of subliminal stimuli has more and more frequently been used to investigate the nature of processes outside of awareness (see Dixon, 1971, 1981). It is of interest to note in light of the research to be described below that the use of subliminal stimuli as a means of investigating unconscious processes was introduced into contemporary psychology by a group of psychoanalytically oriented researchers, beginning with Fisher's pioneering contributions in the fifties (Fisher, 1954, 1956, 1957). Shortly thereafter, Dixon in England followed Fisher's lead (Dixon, 1956, 1958a,b), as did researchers at the Research Center for Mental Health at New York University (Klein, Spence, Holt, \& Gourevitch 1958; Klein \& Holt, 1960; Eagle, 1959; Eagle, Wolitzky, \& Klein, 1966; Pine, 1960, 1961; Spence, 1961, 1964) and researchers at the Menninger Foundation (Luborsky \& Shevrin, 1956; Shevrin \& Luborsky, 1958; Stross \& Shevrin, 1962, 1967). These early studies were criticized by behaviorists such as Goldiamond (1958) and Eriksen (1960) on some of the same methodological grounds as Holender (1986) has more recently revived. Erdelyi (1974) and Bowers (1984), among others, have responded to critiques of this nature. The senior author has reviewed the work of psychoanalytically oriented investigators as they bear on dreaming (Shevrin, 1986) and repression (Shevrin, 1990) and concluded that these studies succeeded in overcoming objections made by critics. (For earlier reviews of this literature see Dixon, 1971, 1981.) In more recent years, within a psychoanalytic frame of reference, the Silverman Subliminal Psychodynamic Activation (SPA) method has generated considerable research (see Balay \& Shevrin, 1988, for a critical evaluation of this body of work.)

Starting in the mid- to late seventies with the work of Marcel $(1975,1983)$, in particular, cognitive psychologists became interested in using subliminal stimuli in research on perception and memory. This body of research has concentrated primarily on demonstrating that semantic processing can occur outside of awareness. Unlike the psychoanalytically oriented researchers, who relied mainly on energy masking to render stimuli subliminal, cognitive investigators have relied 
primarily on backward pattern masking. ${ }^{2}$ This method has not been without its critics (see Holender, 1986), who have raised the objection that the conditions under which thresholds were established in these studies differed significantly from the conditions under which the experimental effects were obtained and were biased in the direction of creating greater consciousness in the experimental condition.

As with Goldiamond's (1958) and Eriksen's (1960) earlier objections, critics raise one fundamental question: Are subjects conscious of more than they report? In response to this criticism, the technology of subliminal perception experiments has undergone a significant change in the direction mainly of obtaining many more stimulus repetitions, guarding against response bias, and in particular demonstrating that when the subject is unaware of a stimulus, its effects are different from when the subject is aware (Cheesman \& Merikle, 1984). This latter criterion was referred to by Shevrin and Dickman (1980) as the strong postulate for unconscious processing.

\section{THE COGNITIVE AND DYNAMIC UNCONSCIOUS}

The major difference between cognitive and dynamic approaches to the unconscious concerns the role of affect and motivation. Although there is growing interest in the relationship of cognition and affect (Zajonc, 1980; Izard, Kagon, \& Zajonc, 1984; Ortony, Clore, \& Collins, 1988), there is little or no interest in defenses, motivation, wishes, desires, and their conflictual interaction, matters of central concern to the psychoanalytic conception of the dynamic unconscious.

However, the psychoanalytic view of the unconscious not only includes a concern with defenses, affect, motivation, and conflict, but is also concerned with the way in which dynamic unconscious processes are organized, or the qualitative differences between conscious and unconscious processing summarized theoretically as the differences between the primary and the secondary process (Freud, 1911/1957; Rapaport, 1959). These qualitative differences are not entirely congruent with the dissociation or disconnection hypotheses offered by Posner and Boies (1971) and Marcel (1983). These latter concepts refer to intrinsic differences between conscious and unconscious processes of a purely cognitive nature (e.g., Posner's multichannel unconscious activation vs single-channel conscious activation; Marcel's attribution of category ascription solely to consciousness). The distinction between primary and secondary processes goes beyond the purely

\footnotetext{
${ }^{2}$ The relationship between energy masking and pattern masking in subliminal research remains an unexplored area. Although Turvey (1973) raised questions about the possibility of central processing for energy-masked stimuli, many studies, as reported in Dixon $(1971,1981)$ and in our own research, have produced repeated positive results with energy masking. Kunst-Wilson and Zajonc (1980), using the same 1-ms exposure condition as in our earlier studies (Shevrin \& Fritzler, 1968), reported positive findings; several replications of the Kunst-Wilson and Zajonc study employed energy masking also with positive results (Seamon, Brody, \& Kauff, 1983a; Seamon, Marsh, \& Brody, 1984). Seamon, Brody, and Kauff (1983b) have used both energy masking and pattern masking in the same experiment with positive results, suggesting that at least with respect to the Kunst-Wilson and Zajonc effect the two methods are equivalent. Nevertheless, the relationship between the effects produced by pattern masking and energy masking requires further examination.
} 
cognitive to encompass shifts in activation as a function of defensive needs, involving conflict and regression (Rapaport, 1959).

As an approach to investigating qualitative differences in thought organization between conscious and unconscious processes as they might bear on dynamic issues, the senior author and co-workers in a series of previous studies employed a specially constructed stimulus in the form of a rebus or pictorial representation of a word (Shevrin \& Luborsky, 1961; Shevrin \& Fritzler, 1968a; Shevrin, 1973). The rebus was a picture of a pen and a knee making up the word "penny." When this stimulus was flashed subliminally at $1 \mathrm{~ms}$, clang or phonetic associations (i.e., pennant or neither) and associations to the rebus word (i.e., nickel, dime, spend) were more likely to occur than when the same rebus was presented supraliminally at $30 \mathrm{~ms}$. These clang and rebus associations were considered similar to the displacements and condensations occurring in dreams and slips that often use phonetic rather than semantic links.

Shevrin and Fisher (1967) demonstrated that subliminal clang and rebus associates to the "penny" rebus occurred after wakenings from Stage 1 REM sleep and semantic associations (i.e. ink, leg) occurred after wakenings from Stage 2 NREM sleep and that both effects were greater than those in associations obtained in the waking state. Stross and Shevrin $(1962,1967)$ had previously demonstrated that hypnosis enhanced semantic subliminal effects, but that a dream was necessary to obtain rebus and clang effects.

Of direct relevance to the research to be reported, these rebus studies demonstrated for the first time in the subliminal literature that an event-related potential (ERP) could differentiate between two subliminal stimuli (Shevrin \& Rennick, 1967; Shevrin \& Fritzler, 1968a,b; Shevrin, Smith, \& Fritzler, 1969, 1970, 1972). A positive-going ERP amplitude at about $200 \mathrm{~ms}$ poststimulus $\left(\mathrm{P}_{200}\right)$ differentiated between the penny rebus and a dummy mockup of the rebus serving as a control. It was also possible to show that clang and rebus associates were correlated with bursts of ERP alpha occurring 1 to $2 \mathrm{~s}$ after stimulus exposure while the semantic effects were positively correlated with the $\mathrm{P}_{200}$ amplitude. Finally, it was found that a measure of repressiveness based on the Rorschach correlated negatively with the size of this differentiating positive-going ERP component: Subjects scoring higher on repressiveness appeared to have a smaller ERP component to the rebus stimulus and gave fewer stimulus-related associations when it was presented subliminally.

These results, each replicated at least once in the series of studies, and their implications have been reviewed by Shevrin (1973). Research done elsewhere has also provided independent support for these ERP subliminal findings. Libet, Alberts, Wright, and Finestein (1967) have demonstrated that an ERP could be detected to a subliminal somatosensory stimulus. Kostandov and Arzumanov (1977) have shown that ERPs discriminate between visually presented subliminal and supraliminal emotional stimuli. Barkoczi, Sera, and Komlosi (1983) and Brandies and Lehmann (1986) have shown that ERPs are associated with hemispheric differences in processing subliminal visual stimuli.

However, there was a significant limitation to the rebus studies from a psychoanalytic standpoint: Nothing bearing directly on affect, motivation, and conflict 
was investigated; the closest these studies came to these factors was in the findings bearing on repressiveness, but these constituted only highly inferential and indirect evidence for dynamic factors. No independent evidence for the existence of unconscious conflict against which repression was operating was provided. Thus, in the next phase of our research we undertook to develop a method that would allow us more directly to address defenses, affect, motivation, and conflict.

\section{THE METHOD}

The method we have developed is based on assessing patients individually so that highly personal renderings of hypothesized unconscious conflicts can be determined. We intended to draw upon the idiographic nature of clinical data and judgment and to use objective laboratory methods to complement the inherent subjectivity of clinical work that relies on complex and often unexplicated inference chains. Two laboratory-based methods provided this objective complement to clinical subjectivity: (1) subliminal and supraliminal exposure of stimuli, and (2) ERPs evoked by these stimuli. A signal analysis of ERPs associated with subliminal and supraliminal exposures of conflict-related stimuli was intended to provide the objective line of evidence converging with subjective clinical assessment.

The method consisted of three components: (1) Clinical assessment and selection of key stimuli, (2) subliminal and supraliminal presentation of these key stimuli, (3) signal analyses of ERPs obtained to these key stimuli.

\section{Clinical Assessment}

The psychodynamic formulation. A clinical team made up of three psychoanalysts and a dynamically oriented psychologist conducted the patient assessments. One member of the team interviewed the patient and another (the psychologist) administrated the tests (WAIS-R, Rorschach, and TAT). The interviews were typical unstructured, psychodynamic dialogues in which the patient was given the opportunity to talk freely about his/her complaints, relationships (including the relationship to the interviewer), and early experiences. Patients were assured in advance that in return for participating in the research they would receive a thorough evaluation by an experienced clinician and a referral for treatment.

The interviews and test protocols were audiorecorded and transcribed for study. Each clinician was required to examine the transcripts and to arrive at a psychodynamic formulation made up of three parts: (a) the patient's description of his/her complaint or presenting symptom, (b) the patient's understanding of this complaint, (c) the underlying unconscious conflict causing the complaint. On the basis of this formulation, the clinicians were to select two groups of words or brief phrases (not exceeding 17 letters including spaces). The first group captured the patient's conscious experience of his/her complaint ( $C$ words). The second group reflected the presumed underlying unconscious conflict (U words). Two control categories were incorporated drawn from the end points of the evaluative (pleasant-unpleasant) dimension of the Osgood Semantic Differential re- 
search (Osgood, May, \& Miron, 1975). The selection of the Osgood unpleasant $(\mathrm{E}-)$ and pleasant $(\mathrm{E}+)$ words was guided by two considerations: (1) by including unpleasant words it was possible to control for unpleasant affect as such which would likely characterize the pathological words; by including $\mathrm{E}+$ words as a comparison category to the three unpleasant categories, a control for emotionality would be provided, (2) research by Chapman (1979) had found that it was possible to discriminate the extremes of the Osgood dimensions on the basis of ERPs.

In addition to written psychodynamic formulations and word selections, the judges met on two occasions to discuss their understanding of the patient. At the first of these two meetings, differences were aired and the interviewer instructed as to what new information to obtain in a third interview that might resolve these differences.

How the judges worked. It has been one of our primary aims to rely on clinical expertise in the word selection process. To depend upon clinical expertise is clearly based on the assumption that such expertise, even if not of the same objective character as the laboratory methods, nonetheless exists. We consider this reliance on expert judgment to be a strength. Often clinical judgments cannot be fully formularized and when researchers attempt to substitute an operational procedure they usually lose what was valuable in the intuitive process (Bond, Hansel, \& Shevrin, 1987). At the same time we recognize that clinical judgments are made within the context of a theoretical frame of reference, in this instance a psychoanalytic frame of reference. But since there are different psychoanalytic frames of reference, it should be noted that the particular frame of reference shared by the clinical judges is based largely on the structural theory elaborated by Arlow and Brenner (1964) and Brenner (1982).

According to structural theory, symptoms and their underlyng conflicts are compromise formations in which id derivatives (or drive factors), ego adaptive capacities (including defenses), and superego functions (self-imposed punishments and rewards) are brought into balance. Thus, a symptom such as a social phobia might be the outcome of a wish to exhibit oneself (id derivative), an inhibition of this wish so that it is not in consciousness or acted upon (ego defense), and a withdrawal from social situations so that the wish cannot be satisfied (superego punishment or deprivation). The reasons why the wish is inhibited and would create a sense of danger and anxiety if admitted into consciousness or acted upon relate to the underlying unconscious conflict.

Our use of psychoanalytic theory draws upon other concepts such as the centrality of the oedipus complex, unfolding psychosexual stages of development, and the significance of unconscious fantasies. However, our method could as easily be used by clinical judges with other theoretical preferences.

The Delphi method. While wishing to use the strengths inherent in expert clinical judgments, we also chose to strengthen the expert judgment process through use of the Delphi method (Linstone \& Turoff, 1975). According to Dalkey, the Delphi method includes the following: (1) "The exercise involves a group; (2) the goal of the exercise is information, i.e., the exercise is an inquiry; (3) the information being sought is uncertain in the minds of the group; (4) some preformulated 
systematic procedure is followed in obtaining the group output" (Linstone \& Turoff, 1975, p. 236).

Dalkey also identified two basic assumptions of the Delphi method: (a) in situations of uncertainty (incomplete information or inadequate theories) expert judgment can be used as a surrogate for direct knowledge, (b) in a wide variety of situations of uncertainty, a group judgment (amalgamating the judgments of a group of experts) is preferable to the judgment of a typical member of the group, the " $n$ heads are better than one" rule. Thus, our aims in using the Delphi method were: (1) to select words on the basis of a corporate or group expert judgment as opposed to depending on the judgments of a single expert, and (2) to use a "preformulated systematic procedure" in obtaining the corporate judgments, one that could be readily understood and replicated by others.

The word selection procedure. The Delphi method was incorporated into the word selection procedure in the following manner (see Table 1 for a summary of the word selection procedure):

(1) Each expert submitted in writing his/her psychodynamic formulation and nominated words from the transcripts.

(2) All the judges' words were put together in a composite list.

(3) Each judge rated all the words on how representative they were of the conscious symptom and unconscious conflict.

(4) The judges met as a group to discuss their views of the patient and the reasons for their word ratings. These discussions provided feedback the judges could then use in their subsequent word ratings.

(5) In addition to discussion as a group, each judge was provided with complete

TABLE 1

Clinical Assessment and Word Selection Procedure

1. Two interviews and psychodiagnostic tests administered.

2. First psychodynamic formulations submitted in writing by all judges.

3. First word selection.

4. First word ratings of list composed of all judges' word selections and $\mathrm{E}+, \mathrm{E}-$ control words.

5. First Clinical Evaluation Team meeting: discussion of differences, questions for third interview.

6. First psychodynamic formulation consensus summaried and approved by all judges.

7. Second psychodynamic formulations submitted in writing by all judges.

8. Second word ratings.

9. Third interview.

10. Third psychodynamic formulations submitted in writing by all judges.

11. Second word selection (from transcript of third interview)

12. Third word ratings (including additional word selections).

13. Second Clinical Evaluation Team meeting.

14. Second and final psychodynamic formulation consensus summaricd and approved by all judges.

15. Fourth and final psychodynamic formulations.

16. Fourth and final word ratings.

17. Final word selection for laboratory presentation (including criteria of frequency of usage and word length). 
rating results from the immediately prior ratings so that this too could be used as feedback and incorporated into subsequent word ratings.

(6) Words were rated on four occasions and, on the second through fourth ratings, judges received feedback from discussion and/or prior ratings to feed forward into their subsequent ratings.

(7) A mathematical formula developed by Robert Marshall combined all four judges' ratings to determine each word's ranking on how well it uniquely reflected the conscious symptom or unconscious conflict (see Appendix A). This final ranking contained the judgments of the corporate expert.

(8) The eight words best reflecting the conscious symptom and eight words best reflecting the unconscious conflict were always chosen from among those in the top fourth of the final ranking.

Based on the MYCIN approach developed by Shortliffe (1976), an 18-point rating scale of category belongingness was used; a score of +9 was assigned to words with maximum belongingness to a particular category, a score of -9 was assigned to a word with minimal belongingness. The formula is based on the assumption that the best conscious symptom word would have an average of +9 rating in the conscious symptoms category across judges and a rating of -9 in the unconscious conflict category across judges. The formula assumes that the best unconscious conflict word would receive an average rating of -9 in the conscious symptom category and +9 in the unconscious conflict category.

In addition to the two pathological categories, 49 of the Osgood highly unpleasant $(\mathrm{E}-)$ or highly pleasant $(\mathrm{E}+)$ words were added to the composite word list and werc rated by the judges at the same time as the pathological catcgorics. Optimally, E - and E + words would be selected that were unrelated to either of the two pathological word categories. They should thus receive a rating of -9 with respect to each of the two pathological categories. Eight $\mathrm{E}-$ and eight $\mathrm{E}+$ words were selected.

In the final step in word selection the four categories were balanced for frequency of usage for English spoken in psychotherapy sessions (Dahl, 1979) and length (see Table 2 for one subject's words and a summary of the final psychodynamic formulation consensus).

We refer to the four word groups as categories following Medin (1989), who has suggested that any category is based on an implicit or explicit theory about the relationships constituting the grouping. Thus, it is the patient's implicit theory concerning the nature of the symptom experience that governs the selection of words describing the symptom. On the other hand, it is the clinician's application of psychoanalytic structural theory that governs the selection of words constituting the unconscious conflict category. The $\mathrm{E}-$ and $\mathrm{E}+$ categories are presumably based on widely held implicit theories as to what constitutes pleasantness and unpleasantness.

The Delphi method should optimize agreement among expert judges and should increase the validity of these judgments. If these corporate judgments refer to actual psychological events, then we might expect to find convergent evidence from the two laboratory-based approaches-subliminal/supraliminal stimulus ex- 
posure and ERP signal analyses. The expectation of convergence with the two laboratory methods is based on previous findings concerning the ability of ERPs to discriminate subliminal stimuli.

In addition to an assessment of unconscious conflict, it would be useful to have an independent measure of defensive organization. We chose a well-standardized instrument for measuring a personality dimension, hysterical-obsessive, for which a reasonable case could be made that the dimension was related to stable but different patterns of defenses. The instrument chosen was the HysteroidObsessoid Questionnaire (HOQ) (Caine \& Hawkins, 1963; Caine \& Hope, 1967). We reasoned that hysteria would be associated with a repressive-avoidant pattern of defenses; obsessionality with an obsessive-intellectualizing pattern of defenses. A number of studies have successfully assessed these stylistic attributes relying mainly on the Rorschach (Schafer, 1954; Shapiro, 1965; Luborsky, Binder, \& Schimek, 1965; Shevrin et al., 1969; Smokler \& Shevrin, 1979). Ludolph (1981) has reported a significant positive correlation $(.70, p<.05)$ between the HOQ and Rorschach based on judgments of hysteroid and obsessoid styles. A high score on the HOQ indicates an hysterical personality organization and a low score an obsessional personality organization.

\section{Subliminal/Supraliminal Laboratory Procedure}

The 32 words making up the four categories selected by the clinicians were presented in a Gerbrand Model T-3A 3-field Dodge-type tachistoscope with field brightness as measured at the eye-piece and surrounding room set at $10.0 \mathrm{ft} /$ lamberts; displays were tested for steady-state and pulse brightness to verify equivalence of the fixation and stimulus fields. The 32 words were presented in six randomized blocks for $1 \mathrm{~ms}$ (subliminal condition) and then at either 30 or 40 ms (supraliminal condition) depending on the duration at which the subject could clearly report seeing the words, determined by presenting two neutral words before the experiment began, first at 30 and then at $40 \mathrm{~ms}$. The 8 words in each category were presented 6 times for a total of 48 presentations of each category for each of the two durations. Words were printed on $4 \times 6$ cards in Helvetica light 18-point type. The white background had approximately four times the reflectance of the black-lettered words. The stimulus cards were numerically coded so that the assistant presenting the words did not know what they were. Subliminality was confirmed by a discrimination series of 40 stimuli presented in the form of 20 paired comparisons at the end of the experiment flashed under the same subliminal condition as during the experiment. Subjects could not discriminate between same and different word pairs, blank pairs, or word/blank pairs at better than chance levels $(50 \%)$. We have also presented two $\mathrm{E}+$ and two $\mathrm{E}-$ words under the same subliminal condition for a total of 120 times for each word in a forced-choice paradigm to 35 subjects. Subjects' guesses were consistently at chance levels (Snodgrass, Shevrin, \& Kopka, in preparation).

ERP Measures. ERPs were derived from three electrode placements with reference to linked ears: $\mathrm{P}_{3}, \mathrm{P}_{4}$, and a special placement one-third of the distance from $\mathrm{C}_{z}$ to $\mathrm{P}_{\mathrm{z}}\left(\mathrm{C}_{\mathrm{z}} \mathrm{P}_{\mathrm{z}}\right)$ found in previous research to provide data discriminating between $\mathrm{E}$ - and $\mathrm{E}+$ word categories (Chapman, 1979). Silver-silver chloride disc elec- 
TABLE 2

\begin{tabular}{|c|c|c|c|}
\hline $\begin{array}{l}\text { Conscious } \\
\text { symptom } \\
\text { words (C) }\end{array}$ & $\begin{array}{c}\text { Unconscious } \\
\text { conflict } \\
\text { words }(\mathbf{U})\end{array}$ & $\begin{array}{c}\text { Osgood } \\
\text { unpleasant } \\
\text { words }(\mathrm{E}-)\end{array}$ & $\begin{array}{c}\text { Osgood } \\
\text { pleasant } \\
\text { words }(E+)\end{array}$ \\
\hline Shorter Breaths & Massaging Muscle & Air Pollution & Pocket Radios \\
\hline Heart Faster & Ripped Apart & Non-Believer & Space Travel \\
\hline Rotten Fish & Parents' Bed & Atomic Bomb & Cleanliness \\
\hline Swallowing & Men Hugging & Poor People & Right Hand \\
\hline Cafeteria & On My Back & Cheating & Pleasant \\
\hline Headache & Stab Me & Cancer & Kindness \\
\hline Nauseous & John & Lying & Quality \\
\hline Tense Up & Evil & Debt & Bath \\
\hline
\end{tabular}

Note. Stimulus words of subject 7, a 20-year-old male suffering from a public eating phobia. The conscious symptom $(C)$ words were all drawn from his answers to interview questions about his experiences while eating in public. The unconscious conflict (U) words were drawn from the subject's interviews and test responses which, in the clinicians' diagnostic judgment, reflect an underlying unconscious conflict with men over dominance and submission that was hypothesized to be related to his phobia. The $\mathrm{E}-$ and $\mathrm{E}+$ words were drawn from the end points of the Osgood evaluative dimension and have been judged to be unrelated to the $\mathrm{C}$ and $\mathrm{U}$ words. The four word categories were balanced for length and frequency of usage.

trodes were used; impedance was below $5 \mathrm{~K} \Omega$; an electrode at the left mastoid served as ground. Data were collected using a 130 -ms prestimulus period and continued for approximately $1 \mathrm{~s}$. Electrode signals were amplified and monitored using a 24-channel Grass Model 8 EEG. Signals contaminated with eye movements, muscle, eye blinks, or alpha waves were rejected either manually or, as in the case of alpha waves, automatically by the computer and were replaced immediately. Gain and bandwidth were set at $7 \mu \mathrm{v} / \mathrm{mm}$ and from 1 to $70 \mathrm{~Hz}$, respectively. Data were sampled at $250 \mathrm{~Hz}$, using an $\mathrm{HP} 1000$ computer system. All individual ERPs were preserved in disk files for subsequent processing.

\section{SUBJECTS}

The most suitable subjects for our research would be patients who were clearly within the neurotic range and suffering from fairly discrete ego-dystonic symptoms sufficiently discomfitting to motivate them to seek treatment. We decided that patients with phobias and pathological grief reactions would meet these criteria. Eleven such subjects have completed the experiment. Of these, eight suffered from phobias (six from social phobias, one with a blood phobia, and one with an agoraphobia), and three suffered from pathological grief reactions. ${ }^{3}$ Seven sub-

\footnotetext{
${ }^{3}$ Of the eight subjects suffering from phobias, six met DSM-III-R criteria for Social Phobia (300.23), one, a blood phobic, met criteria for Simple Phobia (300.29), and one met criteria for Panic Disorder with agoraphobia (300.21). In the ICD-9 diagnostic classification system, all these subjects would meet criteria for Neurotic Disorder, phobic state (300.2). The three subjects judged to have been
} 
jects were men and four were women. All subjects were right-handed and were tested for normal eyesight, if necessary corrected by glasses. No subject reported previous head injuries, psychiatric hospitalizations, or neurological disorders. With one exception, they were all in their twenties and thirties (one woman was in her early forties). Subjects were informed beforehand that the laboratory team knew nothing about their difficulties, other than that they had a psychiatric complaint. Subjects were also told that they could stop the laboratory session at any time and ask to speak to the research director (HS). It was explained to the subjects that they would at times see words that were familiar to them and that at times it might be hard for them to see any words. The laboratory session usually lasted from 3 to $4 \mathrm{~h}$ and was scheduled within a week of completing the clinical assessment. All subjects were referrals from various agencies, such as the University Student Health Service, Outpatient Clinics, etc.

\section{RESULTS}

\section{ERP Signal Analysis}

ERPs can be described in terms of frequencies, amplitudes, latencies, and scalp distributions (Allison, Wood, \& McCarthy, 1986). In a previous report (Shevrin, 1988), a measure based on a Shannon information-thcoretic approach was used in which ERP information properties were measured (Williams, Shevrin, \& Marshall, 1987). This measure differentiated the two pathological categories ( $\mathrm{C}$ and $\mathrm{U}$ words) from the two control categories $(\mathrm{E}+$ and $\mathrm{E}-)$, but failed to differentiate fully the two pathological categories from each other. A new approach was devised that made it possible to analyze the ERPs into discrete time-frequency (t-f) features (Choi, Williams, \& Zaveri, 1987; Choi \& Willilams, 1989; Williams \& Jeong, 1989).

Traditional analyses of brain signals, such as the EEG and the ERP, have relied on amplitude peaks in the time series (e.g., $\mathrm{P}_{300}$ ) or frequency components (e.g., alpha band). For time-varying signals such as the EEG or ERP it is often desirable to know more precisely how their frequency components change with time $(\mathrm{Co}-$ hen, 1989). This result can be achieved by establishing their joint time-frequency distributions (Williams \& Jeong, 1989). Musical notation is one such centuries-old representation of a time-frequency distribution. Each note represents the pitch (frequency) of a sound and its duration. Complex musical pieces consist of many notes with distinct pitches and durations. The trained ear is capable of abstracting these complex relationships. Efforts to devise more mathematically precise time-

suffering from pathological grief reactions were more difficult to fit into diagnostic categories. To the extent that they all shared an abnormal reaction to the death of a close relative, they would qualify as suffering from an adjustment disorder; according to DSM-III-R, however, in each instance the disorder lasted more than 6 months and thus would fail to meet one important DSM-III-R criterion for adjustment disorder, nor would they meet criteria for Uncomplicated Bereavement (V62.82). In all three cases, the main Axis I diagnosis was Dysthymia (300.40). In the ICD-9 diagnostic classification system, these subjects would meet criteria for Adjustment Reaction, prolonged depressive reaction (309.1). 
frequency relationships have been crude by comparison. These approaches have assumed that a tone persists for a certain length of time in order for its frequency to be determined exactly. For example, the spectrogram and sonogram are based on the assumption that the signal remains stationary for a time in order for timefrequency relationships to be determined. These methods require that a window of fixed duration be moved along the signal so the frequencies of the tones lying within the window can be measured. Any variation in the frequency of a component within the window produces a confusing result. The method described by Williams and co-workers (Choi et al., 1987; Williams \& Jeong, 1989) allows for high-resolution descriptions of the time-frequency components of a signal. Using this method, one can now identify precise time-frequency components thus unifying the previous dichotomy between time and frequency and making possible a much more accurate identification of time-varying features. This method surpasses in precision the amplitude components (e.g., $\left.\mathrm{P}_{200}\right)$ used in our previous research. A preliminary account of the application of this new approach to some of our data has been presented elsewhere (Shevrin, Williams, Marshall, Hertel, Bond, \& Brakel, 1988). A brief mathematical account of this method is provided in Appendix B.

On the basis of this new time-frequency analysis the $\mathrm{C}, \mathrm{U}$, and $\mathrm{E}$ - categories were each compared in a discriminant analysis with the $\mathrm{E}+$ category that served as a control or placebo condition. The categories within a pair (e.g., U vs E+) were divided into development and test sets, with the odd presentations $(1,3,5)$ and even presentations $(2,4,6)$ serving alternately as development and test sets. Thus, the 48 ERPs constituting the odd presentations for the $U$ and $E+$ category pair ( 24 from cach catcgory) werc analyzed into their differentiating t-f features and the first 40 of these features were rank ordered in information units (bits) according to their ability to differentiate the two categories (Williams et al., 1987). Features were next combined into clusters of increasing size $(2,3,4 \ldots 19$ features) based on a patterning principle: each feature added was selected to maximize the cluster's capacity to differentiate within category pairs, regardless of original information ranking. According to accepted criteria for pattern recognition, with 24 members in a subset (half the data in a set of 48) a cluster of five time-frequency features should provide maximal capacity for differentiating categories (Devijver \& Kittler, 1982).

Once these feature clusters had been selected for the development set (odd or even), these same features were then applied independently to the test set for validation. Since the actual stimulus was known in each case, a $2 \times 2$ contingency table could easily be constructed for the hits and misses. Chance classification of the test data would be $50 \%$. A percentage correct classification score for each subject for each duration and category was entered into the statistical analyses.

We sought to answer one main question: Would the t-f features differentiate the two clinically selected pathological word categories depending on whether the words had been presented subliminally or supraliminally? In order to answer this question we planned three contrasts. The first planned contrast reflects our particular interest in whether the $\mathrm{U}$ and $\mathrm{C}$ categories would differ from each other in percentage correct classification as a function of duration. The remaining two 
contrasts compare the $\mathrm{U}$ and $\mathrm{C}$ categories separately across durations. In statistical terms, the null hypotheses for the three contrasts would be expressed as:

1. $\left(\mathrm{U}_{\text {sub }}-\mathrm{U}_{\text {sup }}\right)-\left(\mathrm{C}_{\text {sub }}-\mathrm{C}_{\text {sup }}\right)=0$

2. $\left(\mathrm{U}_{\text {sub }}-\mathrm{U}_{\text {sup }}\right)=0$

3. $\left(\mathrm{C}_{\text {sub }}-\mathrm{C}_{\text {sup }}\right)=0$

Statistical analyses and findings. The t-f discriminant analysis was performed on data obtained from electrodes $\mathrm{C}_{z} \mathrm{P}_{z}, \mathrm{P}_{3}$, and $\mathrm{P}_{4}$. The $t-f$ feature analysis also made it possible to combine electrode pairs of special interest in the form of cross-energy, $t-f$ density distributions (see Appendix B for the mathematical derivation of these distributions). Insofar as our stimuli were words, we were particularly interested in the contribution of the left hemisphere as compared to the right hemisphere. For this reason we added $P_{3}$ and $P_{4}$ separately to the $C_{z} P_{z}$ placement found by Chapman (1979) to differentiate between the $\mathrm{E}-$ and the $\mathrm{E}+$ categories. By combining $\mathrm{C}_{2} \mathrm{P}_{2}$ with $\mathrm{P}_{3}$ and $\mathrm{P}_{4}$, respectively, we attempted to take advantage of any commonality between a more central and a lateralized electrode.

Multivariate analyses of the percentage correct classification scores revealed that it was the $\mathrm{C}_{\mathrm{z}} \mathrm{P}_{\mathrm{z}} / \mathrm{P}_{3}$ electrode pair for which a significant category by duration interaction was present: $F(2 / 20)=3.82, p=.039$. For the first planned contrast the difference in percentage correct classification between subliminal and supraliminal durations for the $\mathrm{C}$ and $\mathrm{U}$ categories was significant: $t(20)=2.82, p=$ $.011 .^{4}$ The average difference betwen subliminal and supraliminal durations for the U words was $5.92 \%$ in favor of the subliminal duration (54.78\% vs $49.04 \%$ ) and $-2.65 \%$ in the opposite direction in favor of the supraliminal condition for the $\mathrm{C}$ words $(48.33 \%$ vs $50.99 \%)$. It was this difference that was statistically significant. ${ }^{5}$ The $t-f$ features more correctly classified the $U$ words subliminally and the $\mathrm{C}$ words supraliminally.

For the second planned contrast in which the $U$ words were compared across durations, percentage correct classification was significantly higher subliminally than supraliminally: $t(20)=2.79, p<.014$.

For the third planned contrast in which the $\mathrm{C}$ words were compared across durations, the percentage correct classification was not significantly different $t(20)$ $=-1.25, p>.10$.

In post-hoc testing no significant differences appeared for contrasts involving the E- words. ${ }^{6}$

\footnotetext{
4 The error term for this contrast is the interaction error mean square with 20 degrees of freedom. As Keppel (1982) has pointed out, the interaction mean square is appropriate for use in calculating this interaction contrast unless there were reason to suspect heterogeneity of within-cell variances that is not here the case. These same considerations apply to calculating the appropriate significance levels for the other two planned contrasts. For the three planned contrasts, significance levels had to be less than .017 (Sidak correction set at .05).

${ }^{5}$ Classification results using the development/test method of validation are highly conservative and represent a lower bound on the true performance of the method. If above chance results are obtained, it is highly likely that the true performance of the method would be considerably better given a much larger set of data for development and testing.

${ }^{6}$ Chapman (1979), using hundreds of stimulus repetitions presented supraliminally, was able on the basis of a principal component discriminant analysis to classify $\mathrm{E}+$ and $\mathrm{E}-$ words significantly
} 
Because of the contribution of hemisphere to our results, percentage correct classification scores were correlated between $C_{z} P_{z} / P_{3}$ and $C_{z} P_{z} / P_{4}$. For the $U$ words only, a significant negative correlation was found for the subliminal condition $(-.63, p<.05)$. The correlation for the supraliminal condition was .40 (ns). When the difference between the subliminal and the supraliminal correct classification scores were correlated across hemispheres (high score in favor of the subliminal condition), the correlation for the $\mathrm{U}$ category words was -.70 ( $p<$ .05 ), and nonsignificant for the $\mathrm{C}$ and $\mathrm{E}-$ categories (.30 and .05 , respectively).

How might relationships between frequency and latency in the five $t-f$ feature cluster account for these correct classification results? Analyses were pursued only for the $\mathrm{C}_{\mathrm{z}} \mathrm{P}_{\mathrm{z}} / \mathrm{P}_{3}$ electrode pair. Inspection revealed that there were considerable individual differences in frequency and latency across durations within categories. It was thus decided for the purpose of this exploratory analysis to compare the latencies of the lowest and highest frequencies for each subject within categories and durations and to perform a MANOVA on these data with the two latencies serving as dependent variables.

In determining the relationship between the two latencies the MANOVA program automatically seeks out the linear combination of the two dependent variables which maximizes the differences among the six category by duration cells. In this instance the raw discriminate function coefficients were .00687 for the highest frequency latency and -.00561 for the lowest frequency latency. The contributions of the highest and lowest frequency latencies were of approximately equal magnitude but in opposite directions. Not surprisingly a significant category by duration interaction was found: $F(4 / 36)=4.14, p=.007$, Hotellings test.

Post-hoc Hotelling $\mathrm{T}^{2}$ contrasts were computed using a power correction suggested by Stevens (1986). Three significant contrasts emerged: (1) between subliminal and supraliminal U words: $\mathrm{T}^{2}(2 / 9)=15.51, p<.010 ;(2)$ between subliminal and supraliminal $C$ words: $\mathrm{T}^{2}(2 / 9)=7.23, p<.013$; (3) between subliminal $\mathrm{C}$ and $\mathrm{U}$ words: $\mathrm{T}^{2}(2 / 9)=7.69, p<.011$. No significant differences were found for the E- category.

The direction of these differences revealed that for the $\mathrm{U}$ and $\mathrm{C}$ words mirrorimage reversals between latency and frequency occurred as a function of duration that paralleled the direction of the correct classification results. For the subliminal $U$ words the highest frequency had the shortest latency, while the reverse was true for the subliminal $\mathrm{C}$ words. For the supraliminal $\mathrm{U}$ words the lowest frequency now had the shortest latency, while the reverse was true for the supraliminal $\mathrm{C}$ words. These interactions are displayed in Fig. 1.

\footnotetext{
better than chance. With the same electrode placement, $\mathrm{C}_{\mathbf{z}} \mathrm{P}_{\mathbf{z}}$, and relying solely on the supraliminal presentations, we failed to replicate Chapman's finding for the $E-$ and $E+$ words. However, it is important to take note of several significant differences in our procedure. We employed far fewer stimulus repetitions, the $\mathrm{E}-$ and $\mathrm{E}+$ words were embedded in entirely different verbal contexts (other Osgood dimension words versus personally meaningful words), and a different type of ERP analysis (principal component versus time-frequency features). These substantial differences may account for our failure to replicate Chapman's findings.
} 


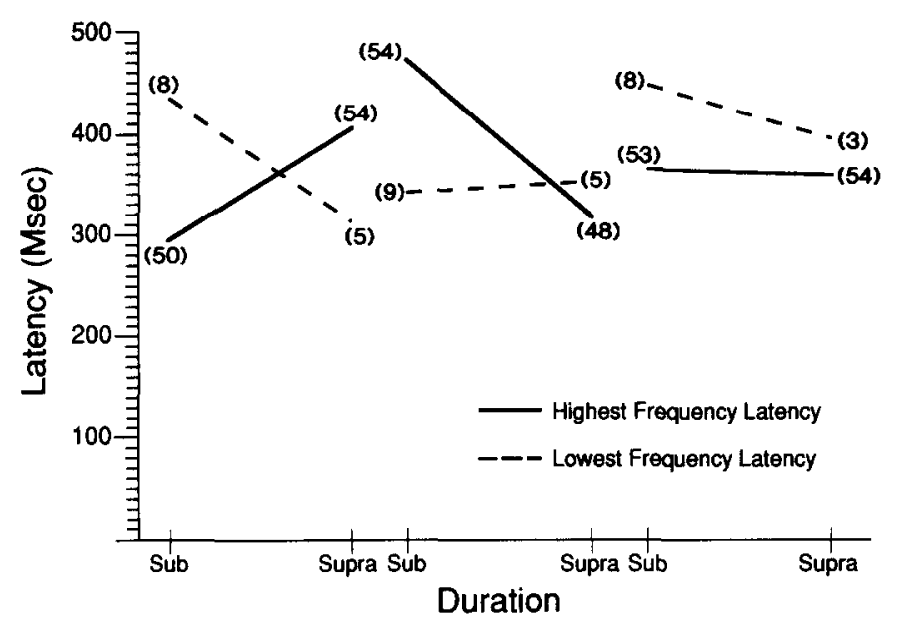

FIG. 1. Relationship between latency and duration for highest and lowest frequencies by word category. (Left) Unconscious conflict words (U); (middle) conscious symptom words (C); (right) Osgood unpleasant words $(\mathrm{E}-)$. Numbers in parentheses are the frequency averages.

If dynamic unconscious processes were involved, we would expect personality and defensive organization to play some role in the differences found between the $\mathrm{U}$ and the $\mathrm{C}$ categories for percentage classification success and the relationships between frequency and latency. HOQ scores were available for 8 of the 11 subjects; 2 subjects were not administered the HOQ through an oversight and 1 subject refused to take the test. When the percentage correct classification difference scores between the subliminal and the supraliminal durations (high score in favor of subliminal condition) were correlated with the HOQ score for the U category, the correlation was $.77(\mathrm{p}<.05)$. For the $\mathrm{C}$ and $\mathrm{E}-$ categories, the correlations were nonsignificant (.16 and -.24 , respectively). The hysteroidrepressive subjects more correctly classified the words related to their unconscious conflicts subliminally than supraliminally. Consistent with repression, these results could be interpreted to mean that the hysteroid-repressive subjects knew unconsciously what they had to remain unaware of consciously.

When we obtained correlations between the HOQ and the highest and lowest frequencies, we again found that for the $U$ words there was a substantial tendency for the correlations to be in opposite directions in the subliminal condition. For the highest frequency the correlation was $.71(p<.05)$, while for the lowest frequency the correlation was -.55 (ns). When the difference between high and low frequencies for a given subject was correlated with the HOQ scores, the correlation for the $\mathrm{U}$ category in the subliminal condition was .81 $(p<.05)$. The only other significant correlation was a correlation of $-.83(p<.05)$ between the highest frequency for the E - category and the HOQ in the subliminal condition. This correlation was in the opposite direction from the one obtained for the $U$ words $(.71$ versus -.83$)$. With respect to latency of the lowest frequency feature, fairly large correlations in opposite directions were found for the $\mathrm{C}$ words 
(subliminal condition: $-.95, p<.01$; supraliminal condition: $.70, p<.10$ ). It is again notable how correlations tend to go in opposite directions as a function of duration and category. Overall, these findings involving the HOQ suggest that personality and defensive organization do indeed play a role in the effects we have been investigating.

\section{DISCUSSION}

Our findings support the claim that the dynamic unconscious can be investigated on the basis of a convergent method in which objective laboratory-based measures complement the subjective, intuitive, theory-rich inferences of the psychoanalytic clinician. The method is an approximation to the physician's reliance on laboratory pathology findings to provide objective evidence for a clinically based diagnosis. Unlike the laboratory pathology findings, however, our laboratory-based methods cannot be viewed as the final arbiter; negative results from the laboratory need not be interpreted as disproving the clinical hypotheses, but simply as not providing support-perhaps other laboratory-based measures would. However, positive findings are significant insofar as they demonstrate that the $\mathrm{C}$ and $\mathrm{U}$ pathological word categories as selected by the clinicians differ in the way in which the brain responds to them. Moreover, these differences support the further claim that the relative failure of t-f ERP features to classify the unconscious conflict words correctly when they were presented supraliminally even though they had been correctly classified subliminally point to defensive activity occurring when these words were presented supraliminally. This is given additional support by the significant correlation between the percentage correct classification difference scores and the HOQ for the U category: The more hysteroid-repressive the subject, the greater the superiority of correct classification subliminally compared to supraliminally for the unconscious conflict words.

The way in which the findings differ depending on duration satisfies a criterion for establishing subliminal effects advocated by Cheesman and Merikle (1984), who have suggested that qualitative differences between conscious and unconscious measures provide powerful methodological support for the existence of subliminal effects. We would add further that these qualitative differences appear most strongly for stimuli related to unconscious conflict and thus underscore the importance of the dynamic unconscious. Had we relied solely on ordinary unpleasant words $(\mathrm{E}-$ ) or even words related to the conscious experience of the symptom, no such differences would have emerged. The earlier rebus studies had shown that ERP parameters $\left(\mathrm{P}_{200}\right.$; ERP alpha) were correlated with differences in the qualitative nature of association processes (semantic versus phonic) depending on whether the stimuli had been presented subliminally or supraliminally; but these results did not speak to the role of unconscious conflict. Our present results, however, show that the content of unconscious conflict elicits different brain responses at an unconscious (subliminal) level than at a conscious (supraliminal) level. It remains to be seen if differences in the nature of associations and in the content of unconscious conflict can be explored in one study in order 
to investigate the psychoanalytic hypothesis that thought processes involving unconscious conflict are organized on the basis of a principle (primary process) different from that of conflict-free thought organization (secondary process), thus shedding light on both the cognitive and the dynamic unconscious.

Our results were found for the electrode pair $\mathrm{C}_{2} \mathrm{P}_{z} / \mathrm{P}_{3}$, but were not found for $\mathrm{C}_{z} \mathrm{P}_{z}, \mathrm{C}_{2} \mathrm{P}_{\mathrm{z}} / \mathrm{P}_{4}, \mathrm{P}_{3}$, and $\mathrm{P}_{4}$. Factors shared by the left hemisphere and a more centrally placed electrode $\left(\mathrm{C}_{z} \mathrm{P}_{z}\right)$ accounted for the outcome. The left hemisphere is generally considered to be involved in sequential, linguistic processing, while the right hemisphere is engaged more in spatial, configurational processing. Our stimuli are words and thus would favor left hemisphere processing. The HOQ findings with respect to percentage correct classification would be consistent with this interpretation: Repression is directed primarily against verbal, ideational representatives or derivatives of unacceptable wishes, rather than at the concrete affective qualities associated with them. Thus, an hysterical patient might blush at a sexual reference but not recall its actual content. Similarly, in split-brain patients, Sperry has reported as noted by Galin (1974) that when a nude figure is presented to the right hemisphere, the patient will blush but not know what they are blushing about. It is inviting to hypothesize that repression acts like a functional splitting of the hemispheres.

These left hemisphere results do not fit, however, with the Galin hypothesis that unconscious processes are mainly to be found in the right hemisphere (Galin, 1974). Rather, our results suggest that unconscious processes may also be found for left hemisphere functions. Our results are consistent with the psychoanalytic structural view that defenses draw upon a wide range of normally occurring psychological functions, such as verbalization, recall, forgetting, attention, etc. (Brenner, 1982; Shevrin \& Bond, in press).

An objection can be raised regarding whether the specific unconscious conflict identified by the clinicians is in fact the cause of the symptom. We may have identified an unconscious conflict, but our results do not necessarily prove a causal connection. This is a sound objection. Perhaps the only way evidence for a causal connection can be gathered is in a psychodynamic treatment, during which the conflict identified previously emerges and understanding results in symptomatic modification. Indeed, Subject 7 (whose words are listed in Table 2) was treated psychodynamically for his social phobia and later reevaluated by the clinical judges at the end of treatment. They came to the conclusion that the anticipated conflict emerged and was to an important extent dealt with and there was in fact symptom relief. The results of this and several other treatments of our research subjects will be reported elsewhere, including the repetition of laboratory results (Shevrin, Brakel, Hertel, and Bond, in preparation).

There are at least three alternate hypotheses that can be offered to account for our results: (1) The words selected for the $U$ category may simply be more unplcasant for the subject than the $\mathrm{C}$ or $\mathrm{E}$ - words when compared to the $\mathrm{E}+$ category and for some unknown reason very unpleasant words follow the pattern of brain responses found, (2) the results are not related to word category as described above, but may be the outcome of several powerful affective words, (3) the unconscious conflict words may indeed be related to conflict and form a 
category but are not necessarily unique to that patient; were these words shown to other psychiatric patients, they would elicit the same pattern of findings. Or, more generally, there may simply be something about the unconscious conflict words, exactly what remains to be determined, that would elicit the same pattern of findings in anyone.

In response to the first hypothesis, we can report that subject ratings on the Osgood evaluative dimension collected after the laboratory procedure was completed showed no difference in unpleasantness between the $\mathrm{C}$ and the $\mathrm{U}$ words. Indeed, there were usually one or two $\mathrm{U}$ category words that had consciously positive affect, such as the word John for Subject 7. It was only unconsciously that John was hypothesized to elicit negative feelings, while consciously the subject considered him to be a close friend. Also, this alternative hypothesis would be hard pressed to account for the actual pattern of findings, while the psychoanalytic hypothesis would have little difficulty.

The second hypothesis is more difficult to answer definitively. We have in further analyses tried to see if our categories can be differentiated from pseudocategories made up of two words each from each of the four categories. Presumably, the pseudo-categories should have no category coherence because they are made up equally of words from the C, U, E - , and E + categories. Results tended to support the belief that we were dealing with real categories and not with the impact of several powerful words. However, this result is not unequivocal; it might still be the case that several words in the real categories, not present in the pseudo-categories, carried the effect. A word-by-word analysis is necessary and is currently being performed.

In response to the third hypothesis, it needs to be noted that the same conflict was not found in every patient even when they had the same symptom (e.g., social phobia). For this reason it is unlikely that the unconscious conflict words would elicit the same pattern of findings in every patient. Although it is logically possible that for some unknown reason the unconscious conflict words for a given patient would elicit the same pattern of findings in everyone, it is highly unlikely given that some of the words could have no meaning at all to anyone other than the patient (e.g., John for Subject 7). Although by no means easy to work out, the best way to answer this objection would be to add a yoked control subject for each experimental subject who would match the experimental subject for symptom, age, and sex, but differ in the nature of the unconscious conflict. The unconscious words from the experimental subject would be given to the yoked subject. The pattern of findings for the unconscious words should be found for the experimental subject but not for the yoked subject.

There is a shortcoming in our design that future research will need to correct. We only employed one duration order: subliminal/supraliminal. Our results may not generalize to the reverse order. Practical time limitations imposed by our method made it difficult to incorporatc a balanced design; another comparable group of patients would need to have been evaluated and tested in the reverse duration order. This work remains for the future. In our current study the words were exposed subliminally to subjects in the absence of any prior awareness of these particular words. Had we started with the reverse order they would have 
already been exposed consciously to the words and subliminal results would have been more difficult to interpret. Against the background of our current findings, however, results with the reverse duration order could be more easily understood. For example, if the results were the same, it would strongly suggest that subliminal processing is relatively insulated from prior conscious exposure and that the same conflict-related words can be responded to differently subliminally and supraliminally, as our present results suggest and clinical experience supports. A patient may talk, as in fact our patients did, about their symptoms, dreams, and fantasies, employing the very words used in the laboratory without, however, being aware of their unconscious significance.

A word needs to be said about the methodological contribution made by the use of subliminal and supraliminal exposures. In effect, subliminal exposure of key stimuli is the closest we can come to an operational definition of an unconscious process. In psychodynamic clinical work we infer the presence of hypothesized unconscious factors but do not have any coercive, operationally clear evidence in support of our inferences; nor can we ordinarily obtain evidence of the operation of a dynamic unconscious factor, such as unconscious conflict, at the time we make our inferences from the presenting material. The senior author has argued elsewhere that from a methodological standpoint the unconscious is an assumption of the psychodynamic method that cannot be proven by data collected with its use (Shevrin, 1984, 1991). The subliminal presentation of words hypothesized to relate to the unconscious conflict obviates this problem: The words are not in consciousness and information about their registration and processing is obtained immediately in the form of ERPs. This latter consideration is also of importance. Unlike most other subliminal studies, our method does not depend on subsequent behavioral responses subject to further interpretation. The signal analysis of the ERPs provides us with an independent, nonbehavioral, concurrent indicator of the effect of the word categories. There is thus objective evidence for the existence in the brain of dynamic, unconscious, conflict-related processing, subject to the possible objections previously discussed.

The category-differentiating sensitivity of the ERP $t-f$ feature analysis is of special interest. First, it must be stressed that this analysis is not the same as an EEG frequency analysis in which a fairly wide time window needs to be used in order to establish a dominant frequency (see Spydell \& Sheer, 1982, for work based on this approach in the study of attention). Nor is it the same as a fast Fourier transform (FFT) analysis that provides a distribution of all the frequencies present in a given EEG episode and their relative power but not their sequence in time. Rather, the t-f feature analysis detects specific time-bound instantaneous frequencies. Our results suggest that changing patterns of frequencies within relatively brief time intervals are markers for conscious and unconscious semantic processing of stimuli related to affect, symptoms, and conflict.

Why the particular patterns of low and high frequency latencies were found requires further study, but it is an intriguing result. For our present purposes, it would not matter what specific ERP parameters were related to the clinically selected word categories; the ERP method was used mainly to provide an objective, nonbehavioral, and immediate correlate of the word categories. Neverthe- 
less, the t-f findings may open the door to a uniquely sensitive brain indicator of complex processing bearing on the nature of the cognitive and dynamic unconscious.

It is, however, of some relevance that there is a fast developing neurophysiological literature based on animal studies and relying on implanted electrodes that provides intriguing evidence for the important role of precisely timed frequencies in brain processes associated with cognitive functioning. Recently Jagadeesh, Gray, and Forster (1992) have reported, based on their investigation of the cat visual cortex, that "rhythmic firing can be synchronized among cells in widespread areas of the visual cortex. The visual stimulus condition under which this process occurs suggests that the synchronization may contribute to the integration of information across broadly displaced parts of the visual field" (p. 252). According to this view, parallel and distributed processes in a purely psychological sense may be integrated neurophysiologically on the basis of frequency features, a possibility consistent with our findings.

Last, although the innovative nature of our method may be conceded, its ultimate utility can be questioned. For one, it could be pointed out that, although statistically significant, the actual magnitudes of the percentage correct classification differences are not very much above chance. For another, out of four analyses (one for each of the electrodes or combined electrodes) only one, $\mathrm{C}_{\mathrm{z}} \mathrm{P}_{\mathrm{z}} / \mathrm{P}_{3}$, produced significant results: moreover, these results depended upon a rather unique, mathematically derived distribution. Finally, the research procedure itself is long, cumbersome, and requires high levels of quite different expertise (e.g., psychodynamic, bioelectrical) and many researchers.

Successful replication would lay to rest at least the first two objections. We also recognize that the procedure is demanding and that this might discourage replication by others. But it is not unusual in science for the early form of a method to be expensive and cumbersome: In biological research the initial stage in isolating and synthesizing an important hormone or enzyme may be extremely difficult; the earliest computers were massive and inefficient compared to the modern desk top PC. But the very isolation of any amount of hormone or the very existence of any computer is of theoretical importance.

There is also some internal evidence that our results may be of greater magnitude than appears to be the case. Intrinsic to our theoretical approach is a multifactorial, interactive model. A symptom is a compromise formation made up of interacting id, ego, and superego factors. We have as yet no clear way theoretically of knowing how to assign weights to these factors in any given instance: Is the symptom caused more by id pressures, superego strictures, or ego weakness? We can only try to keep them all in mind. It would thus follow that the extent to which we incorporated all these factors, the better and perhaps more substantial our results would be.

An illustration of this point is provided by the results from the HOQ, an instrument gauging personality factors related to defenses. When we examine the three planned contrasts, our findings strongly suggest that where the person falls on the hysteroid-obsessoid dimension affects the magnitude of the difference between percentage correct classification subliminally and supraliminally. For the first 
planned contrast in which the $\mathrm{U}$ and $\mathrm{C}$ words were compared for differences between subliminal and supraliminal conditions, we find that for the four most hysteroid subjects, the percentage classification difference between subliminal and supraliminal $U$ words is $8.98 \%$ in favor of the subliminal duration, while for the $\mathrm{C}$ words the percentage classification difference is $-4.45 \%$ in the opposite direction in favor of the supraliminal condition. For the four least hysteroid subjects, the two respective percentages are 1.83 and -4.69 . The overall effect, the difference between the two percentages, for the most hysteroid subjects is $13.43 \%$ while for the least hysteroid subjects it is $6.51 \%$. The most hysteroid subjects demonstrated approximately twice the effect than the least hysteroid subjects. For the second planned contrast, the difference for the $U$ words between subliminal and supraliminal for the most hysteroid subjects is $8.98 \%$ and for the least hysteroid subjects it is $1.82 \%$, a factor of approximately 5 . Finally, for the third planned contrast, the difference between the subliminal and the supraliminal conditions for the $\mathrm{C}$ words is about the same for both high and low hysteroid groups $(-4.45$ and -4.69$)$.

Our next effort could benefit from more fully incorporating the role of defensive organization. Nevertheless, in its current state the method revels new and theoretically relevant phenomena no matter how small in magnitude the effects.

\section{APPENDIX A: WORD SELECTION ALGORITHMS}

Clinicians should be afforded a readily interpretable set of metrics to measure convergence or divergence of opinion on word selections and, at the same time, allow for the assessment of relative degrees of belonging and nonbelonging to the categories of interest.

These considerations have led to a technique of quantifying the various aspects of the word selection process. "Belonging" is quantified for each word in terms of each of the four categories (U, C, E-,$E+$ ) on a scale of +9 to -9 , thus creating a multivariate metric space in which the orthogonal axes are the measures of "belonging" for each category. In this manner the joint properties, as well as the individual properties, of the words may be analyzed. These rankings may also be thought of as measures of "belief" and "disbelief"' in the sense described by Shortliffe (1976), enabling the modeling of the decision process in production rules as in MYCIN.

Properties of interest in word selection are several but not easily confined in a single meaningful metric. An important property is closeness to an ideal category. This implies a distance metric and is readily expressed as a Euclidian distance of the multivariate word ranking from the ideal ranking, that is, a ranking of +9 , $-9,-9,-9$ for a four-category space. Coupled to this property is the distance from other categories. Combining these two distances in a single function serves to provide a meaningful measure of "closeness" to the ideal ranking and "distance" from other categories. In other words, it is a combined or simultaneous measure of "belonging" and lack of ambiguily. The most promising measure among many available seems to be the mean square distance for the distance 
metric and a form of likelihood ratio for the function (Sneath \& Sokal, 1973). A promising function is a product of distance to ideal category and the sum of inverse distances to other categories. The following formula has been developed to capture these dimensions:

$$
D_{\mathrm{c}}-D_{\mathrm{u}}
$$

where

$$
\begin{aligned}
& D_{\mathrm{c}}=V\left(9-C_{\mathrm{mn}}\right)+\left(9+U_{\mathrm{mn}}\right) \\
& D_{\mathrm{u}}=V\left(9+C_{\mathrm{mn}}\right)+\left(9-U_{\mathrm{mn}}\right)
\end{aligned}
$$

$D_{\mathrm{c}} \quad$ = Category distance of conscious symptom words;

$D_{\mathrm{u}}=$ Category distance of unconscious conflict words;

$C_{\mathrm{mn}}=$ Mean of conscious symptom word ratings;

$U_{\mathrm{mn}}=$ Mean of unconscious conflict word ratings.

\section{APPENDIX B: TIME-FREQUENCY DISTRIBUTIONS}

There are a number of ways of representing the energy present in a signal in terms of the relative contributions of the various frequency components at a specific time. The spectrogram method commonly used in speech analysis and the Wigner distribution are two well-known time-frequency energy distributions of Cohen's Class of Distributions (Cohen, 1989). Cohen's class of time-frequency energy distributions is defined for a signal waveform $f(t)$ to be, for a given kernel $\phi(\xi, \tau)$,

$$
C_{f}(t, \omega, \phi)=\frac{1}{2 \pi} \iiint e^{j(\xi t-\tau \omega-\xi \mu)} \phi(\xi, \tau) f\left(\mu+\frac{\tau}{2}\right) f^{*}\left(\mu-\frac{\tau}{2}\right) d \mu d \tau d \xi .
$$

This is the encrgy content of the signal $f(t)$ as a conjoint function of time $(t)$ and frequency $(\omega)$. If two signals, $f(t)$ and $g(t)$, are considered then

$$
C_{f g}(t, \omega, \phi)=\frac{1}{2 \pi} \iiint e^{j(\xi t-\tau \omega-\xi \mu)} \phi(\xi, \tau) f\left(\mu+\frac{\tau}{2}\right) g^{*}\left(\mu-\frac{\tau}{2}\right) d \mu d \tau d \xi .
$$

This form reflects the shared or cross-energy distribution between the two signals as a function of time and frequency. The well-known Wigner distribution results when $\phi(\xi, \tau)=1$. The Wigner distribution has many desirable characteristics, hut suffers from the fact that multiple signals produce strong cross-terms as well as the individual signal contributions. Although mathematically desirable and correct in a theoretical sense, the cross-terms are difficult to interpret visually when a plot of the energy surface as a function of time and frequency is viewed. It is also difficult to apply pattern recognition techniques in the presence of these cross-terms since they result from interactions of significant features in the data and are not unique to a given signal component in and of itself. A new distribution (termed the Reduced Interference Distribution or RID) obtained by careful design of $\phi(\xi, \tau)$ yields a result that retains the contributions of individual signal compo- 
nents while significantly reducing cross-terms (Choi \& Williams, 1989; Williams \& Jeong, 1989). This has made the pattern recognition and classification approach utilized in this report possible. Formulae, incorporating the new RID kernel, were used to obtain time-frequency features for signals derived from two electrodes (e.g., $C_{z} P_{z}$ and $P_{3}, C_{z} P_{z}$ and $P_{4}$ ) (see Eq. (2)).

\section{ACKNOWLEDGMENTS}

Psychoanalysts, psychologists, psychiatrists, biomedical engineers, and computer specialists have collaborated to produce the research results reported in this paper. The research group is divided into clinical and laboratory teams: Serving on the clinical team have been James A. Bond, Ph.D., Linda W. Brakel, M.D., Robert Hatcher, Ph.D., John Hartman, Ph.D., Richard K. Hertel, Ph.D., Susan Miller, Ph.D., Dwarkanath Rao, M.D., and Howard Shevrin, Ph.D. Serving on the laboratory team have been Ramesh Kushwaha, Ph.D., Robert E. Marshall, M.E.E., John Michael Snodgrass, Ph.D., William J. Williams, Ph.D., and Philip S. Wong, Ph.D. Anna Tornow and Nancy Kuzminski have served as EEG technicians. Dorothy Holinger and Michael Kopka assisted in the collection of laboratory data. Leonides D. Iasemides, Hitten P. Zaveri, and E. J. Zheng contributed their skills in signal analysis. Beverly Knickerbocker has diligently, laboriously, and accurately transcribed interview and testing tapes. The research received support in its early stages from the MacArthur Foundation and more recently from the Ford Motor Co., and the National Science Foundation (Grant BCS 9110571), in addition to ongoing support from the Department of Psychiatry, University of Michigan Medical Center. We gratefully acknowledge the special contribution of John Michael Snodgrass, Ph.D., who performed all the statistical analyses cited in this paper.

\section{REFERENCES}

Allison, T., Wood, C. C., \& McCarthy, G. (1986). The central nervous system. In M. G. H. Coles, E. Donchin, \& S. W. Porges (Eds.), Psychophysiology. Oxford: Elsevier.

Arlow, J., \& Brenner, C. (1964). Psychoanalytic concepts and the structural theory. New York: International Universities Press.

Balay, J., \& Shevrin, H. (1988). The subliminal psychodynamic activation method: A critical review. American Psychologist, 43(3), 161-174.

Barkoczi, I., Sera, L., \& Komlosi, A. (1983). Relationships between functional symmetry of the hemispheres, subliminal perception and some defense mechanisms in various experimental settings. Psychologia, 26, 1-20.

Bond, J. A., Hansell, J., \& Shevrin, H. (1987). Locating transference paradigms in psychotherapy transcripts: Reliability of relationship episode location in the core conflictual relationship theme (CCRT) method. Psychotherapy, 24(4), 736-749.

Bowers, K. S. (1984). On being unconsciously influenced and informed. In K. S. Bowers \& D. Meichenbaum (Eds.), The unconscious reconsidered (pp. 227-272). New York: Wiley.

Brandeis, D., \& Lehmann, D. (1986). Event-related potentials of the brain and cognitive processes: Approaches and applications. Neuropsychologia, 24(1), 151-166.

Brenner, C. (1982). The mind in conflict. New York: International Universities Press.

Caine, T. M., \& Hawkins, L. G. (1963). Questionnaire measure of the hysteroid/obsessoid component of personality: The HOQ. Journal of Consulting Psychology, 27, 206-209.

Caine, T. M., \& Hope, K. (1967). Manual of the hysteroid-obsession questionnaire (HOQ). London: Univ. of London Press.

Castaldo, E., \& Shevrin, H. (1970). Different effects of an auditory stimulus as a functiion of rapid eye movement and non-rapid eye movement sleep. Journal of Nervous and Mental Disease, 150, $195-200$. 
Chapman, R. M. (1979). Connotative meaning and averaged evoked potentials. In H. Begleiter (Ed.), Evoked brain potentials and behavior. New York: Plenum.

Cheesman, J., \& Merikle, P. (1984). Priming with and without awareness. Perception and Psychophysics, 36, 387-395.

Choi, H. I., Williams, W. J., \& Zaveri, H. (1987). Analysis of event-related potentials: Time-frequency energy distribution. Biomedical Sciences Instrumentation, 23, 251-258.

Choi, H. I., \& Williams, W. J. (1989). Improved time-frequency representation of multicomponent signals using exponential kernels. IEEE Transactions on Acoustics, Speech and Signal Processing, 37(6), 862-871.

Cohen, L. (1989). Time-frequency distributions: A review. Proceedings IEEE, 77(7), 941-981

Dahl, H. (1979). Word frequencies of spoken American English. Detroit: Verbatim Books: Gate Research Co.

Devijver, P. A., \& Kittler, J. (1982). Pattern recognition: A statistical approach. London: Prentice-Hall.

Dixon, N. F. (1956). Symbolic associations following subliminal stimulation. International Journal of Psychoanalysis, 37, 159-170.

Dixon, N. F. (1958a). The effect of subliminal stimulation upon autonomic and verbal behaviour. Journal of Abnormal and Social Psychology, 57, 29-36.

Dixon, N. F. (1958b). Apparent changes in the visual threshold as a function of subliminal stimulation: A preliminary report. Quarterly Journal of Experimental Psychology, 10, 211-219.

Dixon, N. F. (1971). Subliminal perception: The nature of a controversy. London: McGraw-Hill.

Dixon, N. F. (1981). Preconscious processing. New York: Wiley.

Eagle, M. (1959). The effects of subliminal stimuli of aggressive content upon conscious cognition. Journal of Personality, 23, 48-64.

Eagle, M., Wolitzky, D. L., \& Klein, G. S. (1966). Imagery: Effect of a concealed figure in a stimulus. Science, 151, 837-839.

Erdelyi, M. H. (1974). A new look at the new look: Perceptual defense and vigilance. Psychological Review, 81, 1-25.

Eriksen, C. W. (1960). Discrimination and learning without awareness: A methodological survey and evaluation. Psychological Review, 67, 279-300.

Fisher, C. (1954). Dreams and perception: The role of preconscious and primary modes of perception and dream formation. Journal of the American Psychoanalytic Association, 2, 389-445.

Fisher, C. (1956). Dreams, images, and perception: A study of unconscious-preconscious relationships. Journal of the American Psychoanalytic Association, 4, 5-48.

Fisher, C. (1957). A study of the preliminary stages of the construction of drcams and images. Journal of the American Psychoanalytic Association, 5, 5-60.

Freud, S. (1911/1958). Formulations on the two principles of mental functioning. Standard Edition, 12, 218-226. London: Hogarth Press.

Galin, D. (1974). Implications for psychiatry of left and right cerebral specialization: A neurophysiological content for unconscious processes. Archives of General Psychiatry, 31, 572-583.

Goldiamond, I. (1958). Indicators of perception. I. Subliminal perception, subception, unconscious perception: An analysis in terms of psychophysical indicator methodology. Psychological Bulletin, 55, 373-411.

Holender, D. (1986). Semantic activation without conscious identification. Behavioral and Brain Sciences, 8, 1-66.

Izard, C. E., Kagan, J., \& Zajonc, R. B. (Eds.) (1984). Emotions, cognition and behavior. Cambridge: Cambridge Univ. Press.

Jagadeesh, B., Gray, C. M., \& Forster, D. (1992). Visually evoked oscillations of membrane potential in cells of cat visual cortex. Science, 257, 552-554. 
Keppel, G. (1982). Design and analysis: A researcher's handbook (2nd ed.). Englewood Cliffs, NJ: Prentice-Hall.

Kihlstrom, J. F. (1984). Conscious, subconscious, unconscious: A cognitive perspective. In K. S. Bowers \& D. Meichenbaum (Eds.), The unconscious reconsidered. New York: Wiley.

Kihlstrom, J. F. (1987). The cognitive unconscious. Science, 237, 1445-1452.

Klein, G. S., Spence, D. P., Holt, R. R., \& Gourevitch, S. (1958). Cognition without awareness: Subliminal influences upon conscious thought. Journal of Abnormal and Social Psychology, 54, 167-176.

Klein, G. S., \& Holt, R. R. (1960). Problems and issues in current studies of subliminal activation: In J. G. Peatman \& E. L. Hartley (Eds.), Festschrift for Gardner Murphy (pp. 75-93). New York: Harper \& Row.

Kostandov, E., \& Arzumanov, Y. (1977). Averaged cortical evoked potentials to recognized and non-recognized verbal stimuli. Acta Neurobiologica Experimentalis, 37, 311-324.

Kunst-Wilson, W. R., \& Zajonc, R. D. (1980). Affective discrimination of stimuli that cannot be recognized. Science, 7, 557-558.

Libet, B., Alberts, W. W., Wright, E. W., \& Feinstein, B. (1967). Responses of human somatosensory cortex to stimuli below threshold for conscious sensation. Science, 158, 1597-1600.

Linstone, H. A., \& Turoff, N. (1975). The Delphi method: Techniques and applications. Reading, MA: Addison Wesley.

Luborsky, L., \& Shevrin, H. (1956). Dreams and day-residues: A study of the Poetzl observation. Bulletin of the Menninger Clinic, 20, 135-148.

Luborsky, L., Blinder, B., \& Schimek, J. (1965). Looking, recalling and GSR as a function of defense. Journal of Abnormal Psychology, 70, 270-280.

Ludolf, P. S. (1981). The dissociative tendency: Its relationship to personality style and psychopathology. Unpublished doctoral dissertation. The University of Michigan, Ann Arbor.

Marcel, A.J. (1975). Conscious and unconscious perception: An approach to the relations between phenomenal experience and perceptual processes. Cognitive Psychology, 15(2), 218-300.

Marcel, A. J. (1983). Conscious and unconscious perception: Experiments in visual masking and word recognition. Cognitive Psychology, 15, 197-237.

Medin, D. L. (1989). Concepts and conceptual structure. American Psychologist, 44(12), 1469-1481.

Osgood, C. E., May, W. H., \& Miron, M. S. (1975). Cross-cultural universals of affective meaning. Urbana: Univ. of Illinois Press.

Ortony, A., Clore, G. L., \& Collins, A. (1988). The cognitive structure of emotions. Cambridge: Cambridge Univ. Press.

Pine, F. (1960). Incidental stimulation: A study of preconscious transformation. Journal of Abnormal and Social Psychology, 70, 559-563.

Pine, F. (1961). Incidental versus focal presentation of drive related stimuli. Journal of Abnormal and Social Psychology, 62, 482-490.

Posner, M., \& Boies, S. (1971). Components of attention. Psychological Review, 78(5), 391-408.

Rapaport, D. (1959). The structure of psychoanalytic theory: A systematizing attempt. Psychological Issues, Monograph 6. New York: International Universities Press.

Schafer, R. (1954). Psychoanalytic interpretation in Rorschach testing. New York: Grune \& Stratton.

Seamon, J. G., Brody, N., \& Kauff, D. M. (1983a). Affective discrimination of stimuli that are not recognized: Effects of shadowing, masking and cerebral laterality. Journal of Experimental Psychology: Learning, Memory and Cognition, 9, 544-555.

Seamon, J. G., Brody, N., \& Kauff, D. M. (1983b). Affective discrimination of stimuli that are not recognized. II. Effect of delay between study and test. Bulletin of the Psychonomic Society, 21, $187-189$.

Seamon, J. G., Marsh, R. L., \& Brody, N. (1984). Critical importance of exposure duration for 
affective discrimination of stimuli that are not recognized. Journal of Experimental Psychology: Learning, Memory and Cognition, 10, 465-469.

Shapiro, D. (1965). Neurotic styles. New York: Basic Books.

Shevrin, H. (1973). Brain wave correlates of subliminal stimulation, unconscious attention, primaryand secondary-process thinking and repressiveness. Psychological Issues, Monograph No. 30 , $8(2), 56-87$.

Shevrin, H. (1984). The fate of the five metapsychological principles. Psychoanalytic Inquiry, 4(1), $33-58$.

Shevrin, H. (1986). Subliminal perception and dreaming. Journal of Mind and Behavior, 7(2,3), 379-395.

Shevrin, H. (1988). Unconscious conflict: A convergent psychodynamic and electrophysiological approach. In M. J. Horowitz (Ed.), Psychodynamics and cognition. Chicago: Univ. of Chicago Press.

Shevrin, H. (1990). Subliminal perception and repression. In J. Singer (Ed.), Repression and dissociation: Implications for personality, psychopathology and health. Chicago: Univ. of Chicago Press.

Shevrin, H. (1991). The nature of the psychoanalytic method: Clinical and research implications. Panel presentation, First International Conference on Psychoanalytic Research, International Psychoanalytic Association, London.

Shevrin, H., \& Bond, J. (in press). The unconscious and repressive phenomena. In N. E. Miller \& J. L. Luborsky (Eds.), The handbook on psychodynamic treatment research. New York: Basic Books.

Shevrin, H., \& Dickman, S. (1980). The psychological unconscious: A necessary assumption for all psychological theory? American Psychologist, 35, 421-434.

Shevrin, H., \& Fisher, C. (1967). Changes in the effects of a waking subliminal stimulus as a function of dreaming and non-dreaming sleep. Journal of Abnormal Psychology, 72(4), 362-368.

Shevrin, H., \& Fritzler, D. (1968a). Visual evoked response correlates of unconscious mental processes. Science, 161, 295-298.

Shevrin, H., \& Fritzler, D. (1968b). Brain response correlates of repressiveness. Psychological Reports, 23, 887-892.

Shevrin, H., \& Luborsky, L. (1958). The measurement of preconscious perception in dreams and images: An investigation of the Poetzl phenomenon, Journal of Abnormal and Social Psychology, 56, 285-294.

Shevrin, H., \& Luborsky, L. (1961). The rebus technique: A method for studying primary-process transformations of briefly exposed pictures. Journal of Nervous and Mental Disease, 133, 479-488.

Shevrin, H., \& Rennick, P. (1967). Cortical response to a tactile stimulus during attention, mental arithmetic and free associations. Psychophysiology, 3, 381-388.

Shevrin, H., Smith, W. H., \& Fritzler, D. (1969). Repressiveness as a factor in the subliminal activation of brain and verbal responses. Journal of Nervous and Mental Disease, 149, 261-269.

Shevrin, H., Smith, W. H., \& Fritzler, D. (1970). Subliminally stimulated brain and verbal responses of twins differing in repressiveness. Journal of Abnormal Psychology, 76, 39-46.

Shevrin, H., Smith, W. H., \& Fritzler, D. (1972). Average evoked response and verbal correlates of unconscious mental processes. Psychophysiology, 6(2), 149-162.

Shevrin, H., Williams, W. J., Marshall, R. E., Hertel, R. K., Bond, J. A., \& Brakel, L. A. (1988). Event-related potential indicators of the dynamic unconscious. Presented at the IVth International Conference on Psychophysiology, Prague, Czechoslovakia.

Shevrin, H., Brakel, L. A., Hertel, R., \& Bond, J. A. (1992). Post-treatment changes in event-related potential indicators of unconscious conflict, in preparation.

Shortliffc, E. H. (1976). Computer-based medical consultations: MYCIN. New York: Elsevier. 
Smokler, I., \& Shevrin, H. (1979). Cerebral lateralization and personality style. Archives of General Psychiatry, 36, 949-954.

Sncath, P. H. A., \& Sokal, R. R. (1973). Numerical taxonomy. San Francisco: Freeman.

Snodgrass, M., Shevrin, H., \& Kopka, M. (in preparation). The intentional retrieval of unconscious perceptions: The influences of motivation, task strategy, task preference and word meaning.

Spence, D. P. (1961). The multiple effects of subliminal stimuli. Journal of Personality, 29, 40-53.

Spence, D. P. (1964). Conscious and preconscious influences on recall: Another example of the restricting effects of awareness. Journal of Abnormal and Social Psychology. 68, 92-99.

Spydell, J. D., \& Sheer, D. E. (1982). Effect of problem solving on right and left hemisphere $40 \mathrm{Hertz}$ EEG activity. The Society for Psychophysiological Research, 19(4), 420-425.

Stevens, J. (1986). Applied multivariate statistics for the social sciences. Hillsdale, NJ: Erlbaum.

Stross, L., \& Shevrin, H. (1962). Differences in thought organization between hypnosis and the waking state: An experimental approach. Bulletin of the Menninger Clinic, 26, 237-247.

Stross, L., \& Shevrin, H. (1967). Thought organization in hypnosis and the waking state: The effects of subliminal stimulation in different states of consciousness. Journal of Nervous and Mental Disease, 147, 272-288.

Turvey, M. (1973). On peripheral and central processes in vision: Inferences from an informationprocessing analysis of masking with patterned stimuli. Psychological Review, 80, 1-52.

Williams, W. J., and Jeong, J. (1989). New time-frequency distributions: Theory and applications. IEEE Transactions, CH2692-0000, 1243-1247.

Williams, W. J., Shevrin, H., \& Marshall, R. (1987). Information modeling and analysis of event related potentials. IEEE Transactions on Biomedical Engineering, BME-34(12).

Zajonc, R. D. (1980). Feeling and thinking: Preferences need no inferences. American Psychologist, 35(2), 151-175.

Received March 25, 1992 